\title{
On the influence of Si:Al ratio and hierarchical porosity of FAU zeolites in solid acid catalysed esterification pretreatment of bio-oil
}

\author{
Amin Osatiashtiani $^{1}$ - Begoña Puértolas ${ }^{2}$ - Caio C. S. Oliveira ${ }^{3}$ - Jinesh C. Manayil ${ }^{1}$. \\ Brunella Barbero $^{1}$ - Mark Isaacs ${ }^{1}$ - Chrysoula Michailof ${ }^{4}$. Eleni Heracleous ${ }^{4}$.

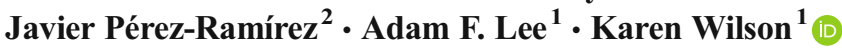

Received: 26 December 2016 / Revised: 6 March 2017 / Accepted: 8 March 2017 /Published online: 5 April 2017

(C) The Author(s) 2017. This article is published with open access at Springerlink.com

\begin{abstract}
A family of faujasite (FAU) zeolites with different $\mathrm{Si}: \mathrm{Al}$ ratio, and/or hierarchical porosity introduced via postsynthetic alkaline desilication treatment, have been evaluated as solid acid catalysts for esterification pretreatments of pyrolysis bio-oil components. Acetic acid esterification with aliphatic and aromatic alcohols including methanol, anisyl alcohol, benzyl alcohol, $p$-cresol and $n$-butanol was first selected as a model reaction to identify the optimum zeolite properties. Materials were fully characterised using $\mathrm{N}_{2}$ porosimetry, ICP, XRD, XPS, FT-IR, pyridine adsorption, $\mathrm{NH}_{3}$ TPD, In-situ ATR and inverse gas chromatography (IGC). IGC demonstrates that the surface polarity and hence hydrophobicity of FAU decreases with increased Si:Al ratio. Despite possessing a higher acid site loading and acetic acid adsorption capacity, high Al-content FAU possess weaker acidity than more siliceous catalysts. Esterification activity increases with acid strength and decreasing surface polarity following the order FAU30>FAU6>FAU2.6. The
\end{abstract}

Electronic supplementary material The online version of this article (doi:10.1007/s13399-017-0254-x) contains supplementary material, which is available to authorized users.

Karen Wilson

k.wilson@aston.ac.uk

1 European Bioenergy Research Institute, Aston University, Birmingham B4 7ET, UK

2 Institute for Chemical and Bioengineering, Department of Chemistry and Applied Biosciences, ETH Zurich, Vladimir-Prelog-Weg 1, CH-8093 Zurich, Switzerland

3 Technological Research Institute (IPT), São Paulo 05508-901, Brazil

4 Chemical Process and Energy Resources Institute, Centre for Research and Technology-Hellas (CPERI/CERTH), 6th km Harilaou-Thermi Road, 57001 Thessaloniki, Greece introduction of mesoporosity through synthesis of a hierarchical HFAU30 material further enhances esterification activity through improved acid site accessibility and hydrophobicity. Methanol was the most reactive alcohol for esterification, and evaluated with HFAU30 for the pretreatment of a real pyrolysis bio-oil, reducing the acid content by $76 \%$ under mild conditions.

Keywords Esterification · Bio-oil · Pyrolysis · Heterogeneous catalysis

\section{Introduction}

The depletion of fossil fuel resources and concerns over climate change and $\mathrm{CO}_{2}$ emissions have driven the quest for clean catalytic technologies for the production of green and renewable energy. Of possible future energy platforms, biomass-derived (nonedible) lignocellulose and triglycerides are the only sustainable sources of carbon that can provide low cost solutions for transportation fuels and organic chemicals $[1,2]$. Despite their promise, significant technical hurdles exist to use of such biomass feedstocks limit their economic deployment.

Biomass pyrolysis in an oxygen-free or oxygen-limited environment is commonly used to produce liquid bio-oil for energy applications. However, depending on the nature of feedstock, reaction temperature and residence time, biooils with different compositions and properties can be generated. The resulting bio-oils typically contain $\mathrm{C}_{1}-\mathrm{C}_{3}$ organic acids which lead to corrosive liquids with low $\mathrm{pH}$ $(\mathrm{pH}=2-3)$ that are inherently unstable at room temperature, deteriorating via polymerisation and condensation reactions on storage. Consequently, the produced bio-oil from 
pyrolysis of biomass suffers from severe limitations that can be only overcome if the bio-oil is upgraded to improve its properties; this represents an area where progress is required in catalyst development, particularly in relation to pretreatment processes to reduce bio-oil acidity and hence improve the lifetime of deoxygenation catalysts employed in subsequent upgrading steps [3, 4].

Esterification is of significant industrial importance for the production of solvents, fragrances and polymers from the reaction of organic acids with alcohols (e.g. polyethylene terephthalate, acrylate esters and cellulose acetate) and emerging as a key pretreatment for the production of biodiesel [5] and advanced biofuels from pyrolysis oils [6]. Esterification of free fatty acid (FFA) impurities present in plant, algal and waste oil feedstocks prevents neutralisation of base catalysts employed in the transesterification of triacyl glyceride components and minimises corrosion of vehicle fuel tanks and engine blocks [7]. In the context of pyrolysis oils, esterification of $\mathrm{C}_{2}-\mathrm{C}_{3}$ acids with short-chain bio-derived alcohols such as methanol, ethanol or butanol would be desirable. To address these issues, development of a noncorrosive and recoverable heterogeneous catalyst for esterification pretreatments is critical [5]. In this respect, various solid acid catalysts have been studied for organic acid esterification, including $\mathrm{SO}_{4} /$ $\mathrm{ZrO}_{2}$ [8-10], sulfonic acid functionalised (hierarchical) mesoporous SBA-15 [7, 11-15] KIT-6 [16] and PMO [17] silicas, Cs-exchanged heteropolyacids [18-22], tungstated zirconia [23], zirconium phosphate [24-26] and $\mathrm{Nafion} / \mathrm{SiO}_{2}$ composite (SAC-13) [27]. Among the solid acid catalysts, zeolites are efficient catalysts for esterification [28-30] due to their strong Brønsted acidity and tunable physical and chemical properties through altering their framework Si:Al ratio and structure.

The application of zeolites in petrochemical processes is long established; however, their application in biorefining and biomass processing is relatively recent [28]. Zeolites are employed in biomass transformation for the depolymerisation of cellulose, hydrolysis of polysaccharides, transformation of triglycerides (transesterification), bio-oil upgrading by fluid catalytic cracking, hydrogenation, hydrodeoxygenation, transformation of sugars and sugar alcohols (aromatisation, dehydration, dehydrogenation, hydrogenation) and glycerol conversion [31]. Among zeolites, faujasite (FAU) is of particular interest due to its large-scale petrochemical application and excellent acidic properties and hydrothermal stability [32]. Highly siliceous faujasite can be obtained by a postsynthesis treatment (dealumination) in which the $\mathrm{Al}$ atom is expelled from the zeolite lattice, forming extra-framework $\mathrm{Al}$ species. There are various methods for dealumination including thermal or hydrothermal treatments, chemical treatments and acids leaching. The resulting material, FAU zeolite, possesses a modified framework Si:Al ratio, structure and acidity which in turn modify catalytic performance [32]. The amount of extra-framework $\mathrm{Al}$ species, formed during the process of dealumination, is believed a key factor influencing catalytic activity [33]. In an early related investigation, Corma and coworkers [28] studied the influence of cation exchange over $\mathrm{NaHY}$ zeolites upon phenylacetic and benzoic acid esterification with ethanol between 25 and $110{ }^{\circ} \mathrm{C}$, showing that only the strongest acid sites, possessing $0-1 \mathrm{Al}$ next-nearest neighbours, were active and hence the best catalysts obtained for $\mathrm{Si}: \mathrm{Al}>15$. Titration of the acid site strength and density via pyridine adsorption indicated that esterification required strong acid sites, with Brønsted acid strength inversely proportional to the number of $\mathrm{Al}$ atoms in the secondary coordination sphere. Acid preadsorption revealed that protonation of the carbonyl group of phenylacetic acid was rate limiting. It was also suggested that dealumination increased surface hydrophobicity, displacing reactively formed water from active sites during esterification and shifting the equilibrium towards the ester, although the hydrophobicity of dealuminated catalysts was not determined.

A limitation of zeolites in liquid phase catalysis is associated with their microporosity [34], which raises issues pertaining to mass transport limitations for bulky substrates. The development of zeolites with either hierarchical pore networks [34-38] or larger more accessible pore diameters is hence of interest [39]. Hierarchical porosity can be introduced into zeolites via templating and/or desilication; the former being part of zeolite synthesis and the latter a postsynthetic modification [40]. Desilication through treatment with alkaline solutions of $\mathrm{Na}_{2} \mathrm{CO}_{3}$ or $\mathrm{NaOH}$ selectively removes Si from zeolites [35, 37, 41]. In a study by Čimek et al., the importance of aluminium removal as a prerequisite to desilication was investigated by varying the dissolution conditions [41]. The synthesis and application of hierarchical and large pore zeolites has been extensively reviewed [39, 40, 42, 43].

While Milina et al. [44] reported the link between different framework types and compositions of zeolites and their activity in acetic acid esterification, here we report the effect of varying Si:Al ratio of a FAU zeolite on its physicochemical properties and catalytic performance in acetic esterification with a range of alcohols obtainable from biomass. Hydrophobic properties of FAU zeolites were explored by inverse gas chromatography, and the influence of pore hierarchy was also investigated, with the optimum zeolite composition evaluated for esterification pretreatment of a thermal pyrolysis oil.

\section{Experimental}

\subsection{Catalyst preparation}

A series of faujasite zeolites with various $\mathrm{Si}: \mathrm{Al}$ ratio was acquired from Zeolyst International. The catalysts were calcined 
in static air at $550{ }^{\circ} \mathrm{C}$ with a heating rate of $5^{\circ} \mathrm{C} \mathrm{min}^{-1}$ for $5 \mathrm{~h}$. The hierarchical zeolite (HFAU30) was obtained by suspending the as-received FAU30 (3.3 g) in an aqueous solution $\left(100 \mathrm{~cm}^{3}\right)$ containing $0.1 \mathrm{M} \mathrm{NaOH}$ and $0.2 \mathrm{M}$ tetrapropylammonium bromide (TPABr) at $65^{\circ} \mathrm{C}$ for $30 \mathrm{~min}$ followed by three consecutive exchanges in aqueous $0.1 \mathrm{M}$ $\mathrm{NH}_{4} \mathrm{NO}_{3}$ with a solid-to-liquid ratio of $10 \mathrm{~g} \mathrm{~L}^{-1}$ at room temperature for $8 \mathrm{~h}$. The resulting material was dried overnight at $65{ }^{\circ} \mathrm{C}$ and calcined in static air at $550{ }^{\circ} \mathrm{C}$ (heating rate $=5{ }^{\circ} \mathrm{C} \mathrm{min}^{-1}$ ) for $5 \mathrm{~h}$. All catalysts were dried at $100{ }^{\circ} \mathrm{C}$ for $1 \mathrm{~h}$ prior to catalytic tests.

\subsection{Catalyst characterisation}

Porosimetry $\mathrm{N}_{2}$ adsorption at $77 \mathrm{~K}$ was undertaken in a Micromeritics TriStar II instrument. Prior to the measurement, the samples were evacuated at $300{ }^{\circ} \mathrm{C}$ for $3 \mathrm{~h}$.

XRD The crystalline nature of FAU zeolites was verified by wide angle X-ray powder diffraction (XRD) on a Bruker D8 Advance diffractometer using the $\mathrm{Cu} \mathrm{K} \alpha$ line in the range $2 \theta=10-80^{\circ}$ with a step size of $0.04^{\circ}$.

XPS X-ray photoelectron spectroscopy (XPS) was performed on a Kratos Axis HSi photoelectron spectrometer equipped with a charge neutraliser and $\mathrm{Mg} \mathrm{K} \alpha \mathrm{X}$-ray source $(h v=1253.6 \mathrm{eV})$. Spectra were recorded at normal emission with an analyser pass energy of $20 \mathrm{eV}$ and $\mathrm{X}$-ray power of $225 \mathrm{~W}$.

ICP-OES The Si and Al contents of the bulk of the samples were determined by inductively coupled plasma optical emission spectroscopy (ICP-OES) on a Horiba Ultima 2 instrument equipped with a photomultiplier tube detection.

$\mathbf{N H}_{3}$ TPD Temperature-programmed desorption of ammonia was performed in a Micromeritics AutoChem II 2920 chemisorption analyser coupled with a MKS Cirrus 2 quadrupole mass spectrometer. The catalyst $(0.1 \mathrm{~g})$ was pretreated in He flow $\left(30 \mathrm{~cm}^{3} \mathrm{~min}^{-1}\right)$ at $550{ }^{\circ} \mathrm{C}$ for $2 \mathrm{~h}$. Afterwards, $10 \mathrm{vol} \%$ of $\mathrm{NH}_{3}$ in $\mathrm{He}\left(30 \mathrm{~cm}^{3} \mathrm{~min}^{-1}\right)$ was adsorbed three times at $200{ }^{\circ} \mathrm{C}$ for $30 \mathrm{~min}$, followed by He purging at the same temperature for $1 \mathrm{~h} . \mathrm{NH}_{3}$ desorption was monitored by mass spectrometry in the range of $200-700{ }^{\circ} \mathrm{C}$ using a heating rate of $10^{\circ} \mathrm{C} \mathrm{min}^{-1}$.

Pyridine adsorption Transmission Fourier transform infrared (FT-IR) of adsorbed pyridine was carried out in a Bruker IFS 66 spectrometer $\left(650-4000 \mathrm{~cm}^{-1}, 4 \mathrm{~cm}^{-1}\right.$ optical resolution, coaddition of 32 scans). Self-supporting wafers of the sample ( 5 ton $\mathrm{m}^{-2}, 50 \mathrm{mg}, 1 \mathrm{~cm}^{2}$ ) were evacuated to $10^{-3} \mathrm{mbar}$ for $4 \mathrm{~h}$ at $420{ }^{\circ} \mathrm{C}$, prior to adsorbing pyridine at room temperature. Gaseous and weakly adsorbed molecules were subsequently removed by evacuation at $200{ }^{\circ} \mathrm{C}$ for $30 \mathrm{~min}$. The total concentrations of Brønsted and Lewis acid sites were calculated from the band area of adsorbed pyridine at 1545 and $1454 \mathrm{~cm}^{-1}$, using a previously determined extinction coefficient of $\varepsilon_{\text {Bronsted }}=1.67 \mathrm{~cm} \mathrm{\mu mol}^{-1}$ and

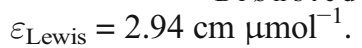

IGC Surface properties were determined according to literature methods $[45,46]$. The measurements were performed at infinite dilution in the Henry region $\left(p / p_{0}=0.04\right)$ to exclude interactions between probe molecules on material surface. Approximately $5 \mathrm{mg}$ of catalyst was packed into a glass column $(300 \mathrm{~mm} \times 2 \mathrm{~mm}$ i.d) by tapping until no cracks or hollows were present in the powder bed. The columns were loosely stoppered with quartz wool in both ends. Then, the powder filled columns were outgassed under helium for $2 \mathrm{~h}$ at $120{ }^{\circ} \mathrm{C}$ to remove adsorbed water and impurities on the surface. Probes including methanol, acetonitrile, ethyl acetate, dichloromethane, $n$-hexane, $n$-heptane, $n$-octane, $n$-nonane and $n$-decane were carried into the column by helium with a gas flow rate of $10 \mathrm{sccm}$ (standard cubic centimeter per minute), and the retention times were detected by a flame ionisation detector (FID). The dead volume, the retention volume if there is no interaction between probe and solid, was calculated based on the elution time of methane which was run at a concentration of $0.1 p / p_{0}$, where $p$ is the partial pressure and $p_{0}$ is the saturation pressure. Five alkanes (i.e. hexane, heptane, octane, nonane and decane) were used to determine the dispersive surface energy $\left(\gamma_{\mathrm{s}}^{\mathrm{d}}\right)$, and four polar probes (i.e. methanol and ethyl acetate, dichloromethane and acetonitrile) were used to determine the polar energy $\left(\gamma_{\mathrm{s}}^{\mathrm{p}}\right)$. All the samples were recorded at identical IGC conditions $\left(T=120{ }^{\circ} \mathrm{C}\right.$, $F=10 \mathrm{ml} \mathrm{min}^{-1}$ ), and all the reagents have high purity $(99 \%)$. The surface polarity $\left(\gamma_{\mathrm{p}}\right)$ was then calculated as the ratio of the polar component to the total surface energy [47].

In situ ATR Infrared spectra were recorded on a Thermo Nicolet FT-IR spectrometer, equipped with a liquid nitrogen cooled MCT (mercury cadmium telluride) detector and an external attachment for ATR-IR measurements. The ATR crystal for a liquid flow-through cell is made of $\mathrm{ZnSe}$ and has trapezoid shape and has dimensions of $80 \mathrm{~mm} \times 10 \mathrm{~mm} \times 4 \mathrm{~mm}$, resulting in ten reflections for a $45^{\circ}$ reflection crystal. The spectrometer was constantly purged with nitrogen to avoid $\mathrm{H}_{2} \mathrm{O}$ and $\mathrm{CO}_{2}$ contamination. All spectra were measured at room temperature at a resolution of $4 \mathrm{~cm}^{-1}$, using the crystal spectra as background. Methanol subtraction and baseline corrections were performed to eliminate the strong signal due to the solvent and minor fluctuations due to instrumental instabilities, respectively. A slurry of catalyst powder was prepared from $30 \mathrm{mg}$ catalyst and $3 \mathrm{ml}$ methanol to yield a thin layer of catalyst. After sonication for $15 \mathrm{~min}$, thin films were formed by dropping the slurry onto a $\mathrm{ZnSe}$ internal reflection element (IRE). The solvent was evaporated at ambient temperature overnight to obtain a uniform 
thin layer of catalyst on the ZnSe crystal. First methanol was passed through the cell and over the catalyst to saturate the catalyst surface with methanol for half an hour. Then, a solution of acetic acid in methanol with concentration of $0.1 \mathrm{M}$ at a flow rate of $0.8 \mathrm{ml} \mathrm{min}^{-1}$ was passed over the catalyst film by means of a syringe pump for another half an hour. Finally, acetic acid was removed from catalyst surface by flushing with pure methanol. A schematic of the experimental setup of flow cell used for the study of ATR-IR spectroscopy is given in Fig. S1.

\subsection{Catalytic tests}

Batch esterification was performed using a Radleys Carousel Reactor Station at atmospheric pressure, unless for reactions with methanol which were performed in Ace pressure flasks equipped with a deep tube and valve, under autogenous pressure. $25 \mathrm{mmol}$ alcohol ( $p$-cresol, $n$-butanol, benzyl alcohol, anisyl alcohol and methanol, Sigma-Aldrich), $5 \mathrm{mmol}$ of acetic acid (Fisher Scientific), $10 \mathrm{ml}$ toluene (Fisher Scientific) as solvent and $0.5 \mathrm{mmol}$ of dihexyl ether (SigmaAldrich) as an internal standard were added to the reactor under stirring at $100{ }^{\circ} \mathrm{C} .100 \mathrm{mg}$ of catalyst was also added to the reaction after $1 \mathrm{~h}$ drying at $100{ }^{\circ} \mathrm{C}$. For reactions with acid:alcohol ratio $=1$ or 5 , the amount of acid and alcohol adjusted, respectively. Aliquots of the reaction mixture periodically withdrawn and filtered and analysed on a Varian 3900 GC equipped with a Phenomenex ZB-50 column. All catalytic profiles are an average of three injections per sample. Conversions reported are based upon change in the concentration of acetic acid, with initial rates calculated over the first hour of reaction, wherein the conversion profile was linear. Turnover frequencies (TOFs) were determined from the initial rate of acetic acid conversion (from the linear portion of the reaction profile) normalised to the Brønsted acid site loadings calculated from pyridine adsorption.

Bio-oil from thermal pyrolysis of oak woodchips was provided by the Centre for Research and Technology-Hellas (CERTH). The measurement of bio-oil acid content was carried out according to modified D664A acid number titration method [48]. Briefly, $1 \mathrm{~g}$ of bio-oil was added into $100 \mathrm{ml}$ ethylene glycol/water solution (95:5 vol:vol), and then the mixture was titrated with $0.1 \mathrm{~N} \mathrm{KOH}$ solution in 2-propanol, and the $\mathrm{pH}$ of the mixture was monitored by a pH meter (Jenway 3510) until pH 7 was obtained. For the esterification of bio-oil, the equivalent mass of $5 \mathrm{mmol}$ acid-containing bio-oil was mixed with $150 \mathrm{mmol}$ methanol, and $100 \mathrm{mg}$ of catalyst and the reaction was carried out at $100{ }^{\circ} \mathrm{C}$ in a sealed Ace pressure flask. After $3 \mathrm{~h}$, the reaction was stopped by cooling down the flask. Then, a sample was withdrawn, filtered and titrated with similar method as explained before (Fig. 1).

Bio-oil characterisation was obtained by $\mathrm{GC} \times \mathrm{GC}$-ToFMS, after proper dilution in $\mathrm{MeOH}$ and without any other pretreatment. The GC $\times$ GC analytical system was an Agilent 7890A GC

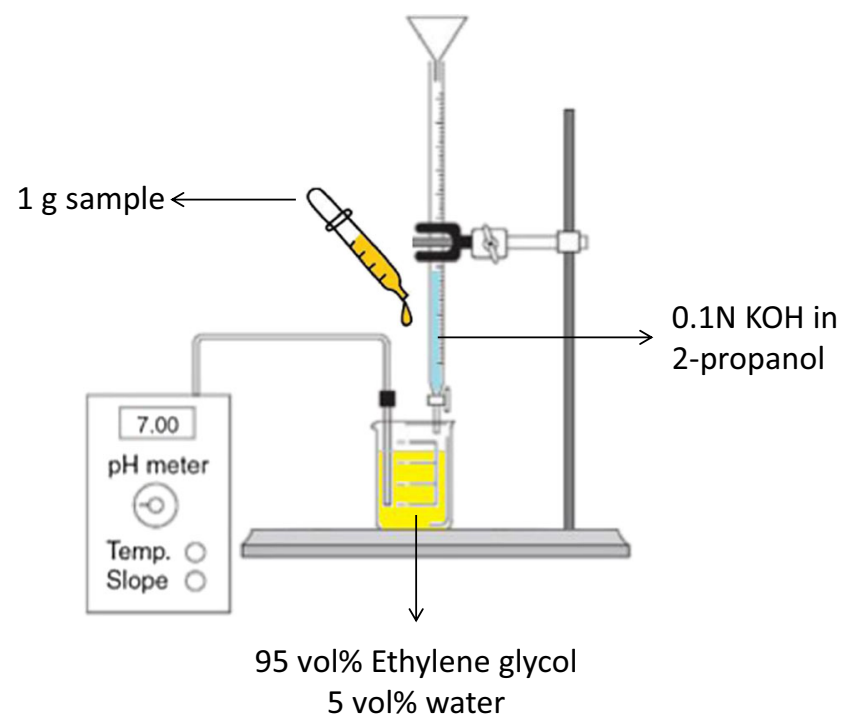

Fig. 1 Bio-oil acid content measurement by modified D664A acid number titration method

with injector Agilent7683B series (Agilent Technologies, PaloAlto, CA, USA) connected to a Pegasus 4D time-of-flight mass spectrometer from Leco Instruments (St. Joseph, MI, USA). The first chromatographic separation was performed with an apolar column BPX-5 (5\% phenyl polysilphenylene-siloxane) $30 \mathrm{~m}$, I.D. $0.25 \mathrm{~mm}$, d.f. $0.25 \mu \mathrm{m}$. The second dimensional column was situated in a secondary internal oven and was a BPX-50 (50\% phenyl polysilphenylene-siloxane) $1.5 \mathrm{~m}$, I.D. $0.1 \mathrm{~mm}$, d.f. $0.1 \mu \mathrm{m}$, both from SGE Analytical Science Pty Ltd. (Australia). Cryofocusing by liquid nitrogen and a quad jet dual stage modulator (Zoex, Houston, TX, USA) was applied. Instrument control, data acquisition and data processing were done by the ChromaToF (Leco) software. The ToFMS operated at an acquisition rate of 100 spectra and a mass range of $\mathrm{m} / \mathrm{z} 45$ $400 \mathrm{amu}$. The modulation period was $5 \mathrm{~s}$. The carrier gas ( $\mathrm{He}$ grade 5) flow rate was $1 \mathrm{ml} \mathrm{min}^{-1}$, injection volume of $0.5 \mu \mathrm{L}$ at a split ratio of $1: 20$ and an injection temperature of $250{ }^{\circ} \mathrm{C}$. Temperature programming was performed at an initial temperature of $35{ }^{\circ} \mathrm{C}$ of the primary $\mathrm{GC}$ oven and was kept stable for $10 \mathrm{~min}$. Then, the temperature increased at a rate of $3{ }^{\circ} \mathrm{C} \mathrm{min}{ }^{-1}$ up to $250^{\circ} \mathrm{C}$, and afterwards with a rate of $15^{\circ} \mathrm{C} \mathrm{min}^{-1}$ up to the final temperature of $330^{\circ} \mathrm{C}$, where it was kept stable until the end of the program. Total run time was $102 \mathrm{~min}$. The secondary oven was programmed $15{ }^{\circ} \mathrm{C}$ ahead of the primary GC oven gradient. Modulator temperature offset was $30^{\circ} \mathrm{C}$. The data acquisition and peak identification were based on the NIST05 library, using as minimum identification criteria similarity of 700 and $\mathrm{S} / \mathrm{N}$ ratio of 50 . The classification of the compounds was performed by borderline group type classification [49].

Recycle tests were performed by recovering the HFAU30 after $3 \mathrm{~h}$ esterification of thermal pyrolysis bio-oil via filtration. The spent catalyst was washed with $200 \mathrm{ml}$ methanol and 
dried at $80{ }^{\circ} \mathrm{C}$ overnight. Half of the recovered catalyst was then calcined in a flow of $\mathrm{O}_{2}$ at $550{ }^{\circ} \mathrm{C}$ for $2 \mathrm{~h}$.

\section{Results and discussion}

\subsection{Catalyst characterisation}

Figure 2 shows the $\mathrm{N}_{2}$ adsorption-desorption isotherms for the series of FAU zeolites under investigation, which show a progressive development of the hysteresis loop and intraparticle mesoporosity as the $\mathrm{Si} A \mathrm{Al}$ ratio of the zeolites increases. A further enhancement in mesoporosity is observed upon alkaline treatment of FAU30 to generate HFAU30, consistent with previous reports $[50,51]$. XRD shown in Fig. S2 confirms that all FAU catalysts are highly crystalline, and that crystallinity of FAU30 sample was preserved after alkali treatment.

XPS analysis was carried out to analyse the surface composition and probe the changes in the surface properties upon variation in $\mathrm{Si}$ :Al ratio (Fig. 3). Table $\mathrm{S} 1$ reports the $\mathrm{Si}: \mathrm{Al}$ surface and bulk ratios, as determined by XPS and ICP, respectively, the values for which are consistent, suggesting the aluminium is evenly distributed throughout the zeolite framework. Perturbation of the $\mathrm{Si} 2 \mathrm{p}$ region was observed with increasing $\mathrm{Al}$ content, previously attributed to the generation of $\mathrm{Si}-\mathrm{O}-\mathrm{Al}$ species (102 eV binding energy) [52], whose surface concentration was proportional to Al content (Fig. S3). The $\mathrm{O}$ 1s spectra also reveals the emergence of a new $\mathrm{O}$ state $\sim 531 \mathrm{eV}$ with increasing $\mathrm{Al}$ content and is likewise attributed to $\mathrm{Si}-\mathrm{O}-\mathrm{Al}$ species.

Zeolite acidity was probed by $\mathrm{NH}_{3}$ TPD and pyridine adsorption (FT-IR) to quantify the number and type of acid sites, and the results of which are summarised in

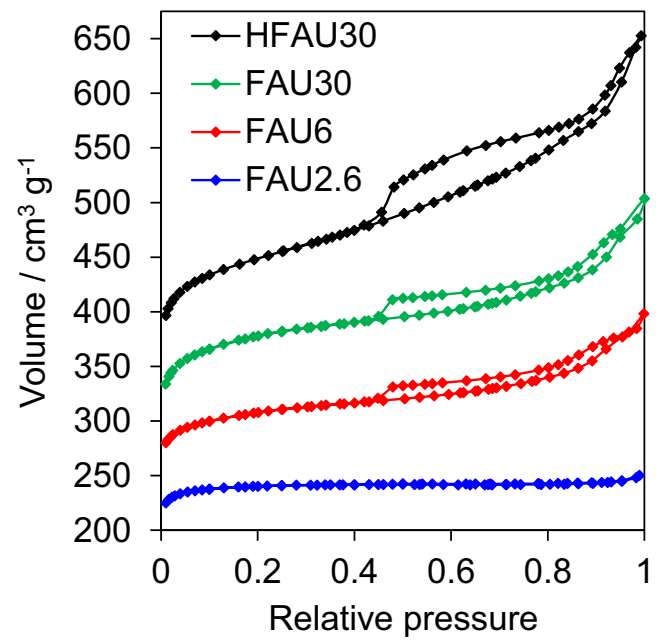

Fig. $2 \mathrm{~N}_{2}$ porosimetry isotherms for FAU zeolites (isotherms were off set for clarity)
Table $1 . \mathrm{NH}_{3}$ TPD revealed that the acid site density of FAU zeolites decreased significantly with increasing Si:Al ratio (Fig. 4), although there was no systematic variation in acid strength and pyridine adsorption showed minimal change in the corresponding Lewis:Brønsted ratio. Alkali etching to produce the mesoporous HFAU30 material did not significantly alter the acid site loading, but increased the Lewis:Brønsted ratio consistent with surface defects formation upon etching. [53]

IGC was employed to determine the surface polarity of zeolites, which is calculated from the dispersive and specific surface energies shown in Table 2. Surface polarity varies inversely with hydrophobicity and was found to decrease with increasing $\mathrm{Si}$ Al ratio for the FAU samples, dropping considerably for the hierarchical HFAU30 zeolite sample. Considering the surface polarity of hydrophobic materials such as polyethylene (0.0) and PVC (0.05), and hydrophilic Pharmatose P450 (0.81) [54], polarity variations across the FAU family were relatively small, except for the HFAU30. The change in polarity of FAU zeolites is consistent with the expected increased density of $\equiv \mathrm{Si}-\mathrm{O}-\mathrm{Si} \equiv$ centres as the $\mathrm{Si}$ :Al ratio increases [55] and is in good agreement with studies of water adsorption on zeolites, where increased nonpolar $\equiv \mathrm{Si}-\mathrm{O}-\mathrm{Si} \equiv$ centres leads to increased hydrophobicity [56]. The specific free energy of adsorption of methanol $\left(-\Delta \mathrm{G}_{\mathrm{ads}}\right.$ SP $\left.\mathrm{MeOH}\right)$ also decreased with increasing $\mathrm{Si}$ :Al ratio indicative of a weaker interaction of polar molecules over surfaces with increased $\equiv \mathrm{Si}-\mathrm{O}-\mathrm{Si} \equiv$ groups. Surface polarity is determined by comparing the elution of (relatively small) polar and (relatively bulky) alkane probe molecules through each zeolite. Fast elution indicates a poor interaction with the surface and hence a dissimilar chemical nature between probe molecule and zeolite. Enhanced transport of alkanes purely through mesopore introduction would therefore result in an apparent increase in surface polarity, the opposite to the change observed in Table 2, wherein HFAU30 exhibits a decreased surface polarity relative to its microporous counterpart. The greater hydrophobicity of HFAU30 relative to FAU30 is also evident from the lower $-\Delta \mathrm{G}_{\mathrm{ads}}{ }^{\mathrm{SP}} \mathrm{MeOH}$ of the former and hence is not an artefact of superior mass transport due to mesopores. The lower surface polarity of HFAU30 may well reflect increased surface roughness due to the etching pretreatment. Increasing zeolite hydrophobicity may promote esterification through the displacement of reactively formed water from active sites which may otherwise cause reversible site blocking [57].

In situ, ATR-IR studies of acetic acid adsorption were further undertaken to assess the impact of $\mathrm{Si}: \mathrm{Al}$ ratio on the adsorption behaviour of the parent FAU zeolites. Figures S4-S6 show the resulting vibrational spectra obtained during acetic acid adsorption from methanolic solution. Rapid surface saturation was 

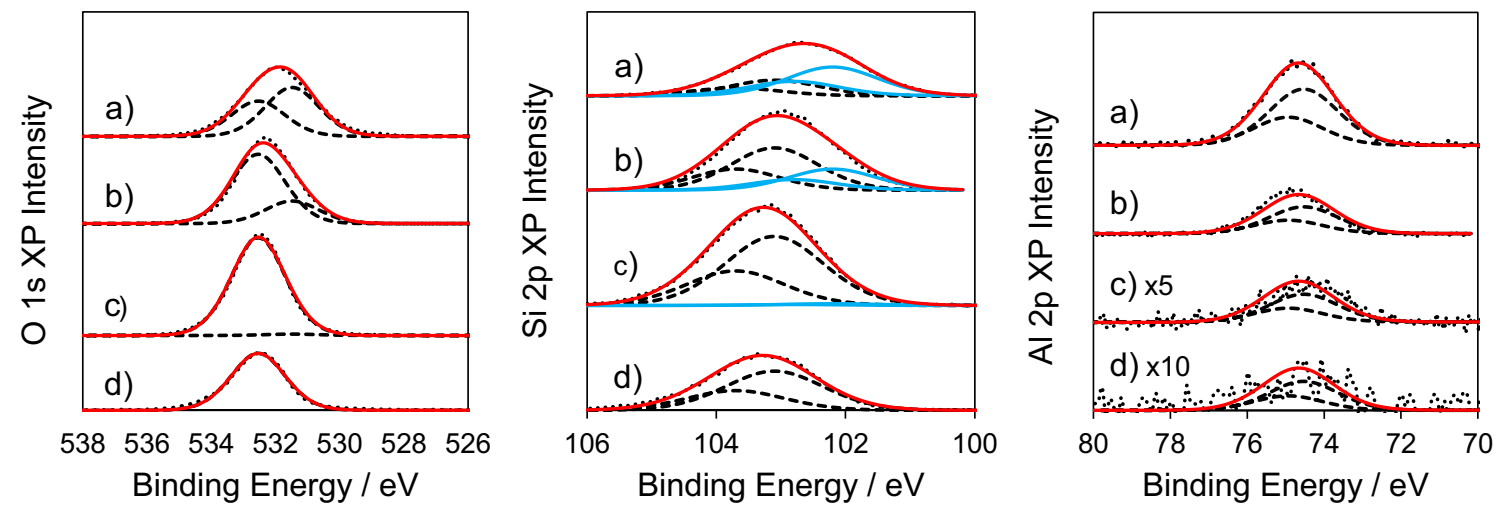

Fig. 3 High resolution XP spectra of O 1s, Si 2p and Al 2p for a FAU2.6, b FAU6, c FAU30 and d HFAU30 zeolite catalysts

observed within 10 min of acetic acid addition to a methanol flow as seen by the growth and plateauing of a $1710 \mathrm{~cm}^{-1}$ band assigned to acetic acid hydrogen bonded via $\mathrm{C}=\mathrm{O}$ to surface hydroxyls, a broad band at $1400 \mathrm{~cm}^{-1}$ in the region for $\delta_{\text {asym }}$ of $\mathrm{CH}_{3}$ and $v_{\text {sym }}$ of $\mathrm{COO}^{-}$and a $1270 \mathrm{~cm}^{-1}$ band attributed to the $\mathrm{C}-\mathrm{O}$ band $\left(\gamma_{\mathrm{C}-\mathrm{O}}\right)$ [58]. The concomitant loss of surface methoxy groups observed as a broad negative peak between 3100 and $2800 \mathrm{~cm}^{-1}$ (Fig. S7) suggests that acetic acid displaces methanol from the zeolite surface. The simultaneous growth of acetic acid features and loss of methoxy species is indicative of competitive adsorption between methanol and acetic acid and consistent with a Langmuir-Hinshelwood surface reaction model for esterification.

Figure 5 shows the integrated peak area of the $\gamma_{\mathrm{C}-\mathrm{O}}$ $\left(1270 \mathrm{~cm}^{-1}\right)$ band during acetic acid adsorption/desorption over the FAU zeolites and reveals that the saturation coverage of acetic acid is inversely proportional to Si:Al ratio (Fig. 5 inset) and hence directly proportional to acid site density and surface polarity, consistent with vapour phase IR measurements [58] that suggest only zeolitic bridging hydroxyls $\mathrm{Si}-$ $\mathrm{OH}-\mathrm{Al}$ (zeol) are able to reactively adsorb acetic acid via:

$$
\begin{aligned}
& \text { zeol- } \mathrm{OH}+\mathrm{HOOC}-\mathrm{CH}_{3} \rightarrow \text { zeol- } \mathrm{OH}_{2}{ }^{+} \\
& \quad+{ }^{-} \mathrm{OOC}-\mathrm{CH}_{3} \rightarrow \mathrm{zeol}^{+}+{ }^{-} \mathrm{OOC}-\mathrm{CH}_{3}+\mathrm{H}_{2} \mathrm{O}
\end{aligned}
$$

\subsection{Catalytic tests}

The utility of FAU zeolite family of materials for the esterification of acetic acid with various alcohols (Fig. 6) was subsequently explored in toluene as a simulated bio-oil matrix. Reaction profiles are shown in Fig. S8.

Figure 7 illustrates the performance of the FAU zeolites with different $\mathrm{Si}: \mathrm{Al}$ ratios and the hierarchical version of FAU30, in esterification of acetic acid with various alcohols. The first striking observation is that methanol is the most reactive alcohol among the tested alcohols, followed by anisyl alcohol, benzyl alcohol, $p$-cresol and butanol. The higher reactivity of methanol is explicable by a LangmuirHinshelwood bimolecular surface reaction model in which coordination of the alcohol and the organic acid at adjacent Brønsted acid sites are necessary and likely reflect both electronic and steric effects. For alcohols, increased alkyl chain length (or addition of other organic groups such as aromatic rings) is accompanied by enhanced electron-donating properties which are expected to destabilise the protonated transition state, hence slowing esterification. Smaller alcohols are also expected to adsorb more weakly relative to longer chain alcohols (of higher pKa which experience greater dispersive interactions with any surface), with the latter favouring alkoxide formation and concomitant site blocking and hence lower

\begin{tabular}{|c|c|c|c|c|c|c|c|c|}
\hline Catalyst & $\begin{array}{l}\text { Surface area }{ }^{\mathrm{a}} / \\
\mathrm{m}^{2} \mathrm{~g}^{-1}\end{array}$ & $\begin{array}{l}\text { Mesopore } \\
\text { area } / \mathrm{m}^{2} \mathrm{~g}^{-1}\end{array}$ & $\begin{array}{l}\text { Micropore volume/ } \\
\mathrm{cm}^{3} \mathrm{~g}^{-1}\end{array}$ & $\begin{array}{l}\text { Bulk Si/Al } \\
\text { ratio }^{\text {b }}\end{array}$ & $\begin{array}{l}\text { Surface Si/Al } \\
\text { ratio }^{c}\end{array}$ & $\begin{array}{l}\mathrm{C}_{\text {Lewis }}^{\mathrm{d}} / \\
\text { mmol g }^{-1}\end{array}$ & $\begin{array}{l}\mathrm{C}_{\text {Brønsted }}{ }^{\mathrm{d}} / \\
\mathrm{mmol} \mathrm{g}^{-1}\end{array}$ & $\begin{array}{l}\text { Lewis:Brønsted } \\
\text { ratio }\end{array}$ \\
\hline FAU2.6 & 718 & 24 & 0.36 & 2.5 & 1.4 & 0.21 & 0.58 & 0.4 \\
\hline FAU6 & 666 & 120 & 0.28 & 5.9 & 4.4 & 0.11 & 0.26 & 0.4 \\
\hline FAU30 & 797 & 171 & 0.33 & 29.9 & 25.9 & 0.04 & 0.15 & 0.3 \\
\hline HFAU30 & 786 & 302 & 0.25 & 23.2 & 23.0 & 0.08 & 0.14 & 0.6 \\
\hline
\end{tabular}

Table 1 Physicochemical properties of FAU zeolites with various $\mathrm{Si} / \mathrm{Al}$ ratio

${ }^{\mathrm{a}} \mathrm{BET}$

${ }^{\mathrm{b}}$ ICP-OES

${ }^{\mathrm{c}} \mathrm{XPS}$

${ }^{\mathrm{d}}$ pyridine adsorption/FT-IR 


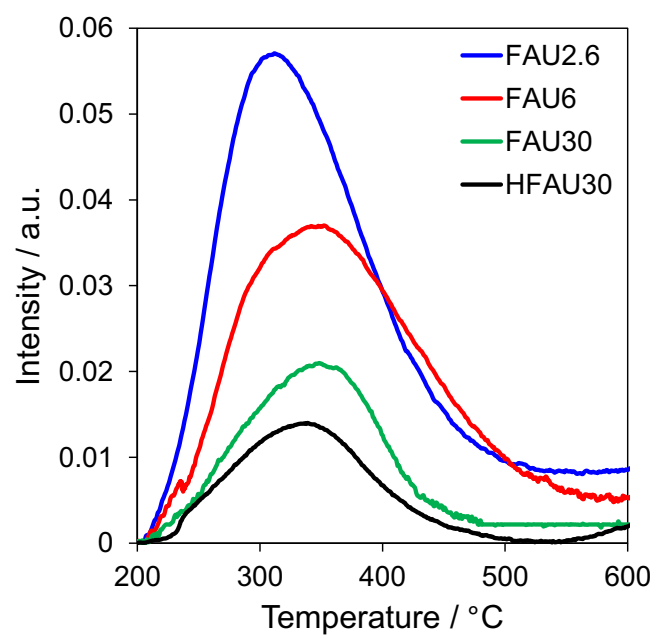

Fig. $4 \mathrm{NH}_{3} \mathrm{TPD}$ on FAU zeolites

reactivity. More sterically demanding alcohols may also experience poorer configurational access to protonated (or activated) carboxylates due to increased distance from neighbouring acids sites. Diffusion limitations may also restrict the accessibility of in-pore acid sites for bulky alcohols contributing to their lower TOFs [59]. Irrespective of the alcohol type or saturation acetic acid coverage, the per site activity increased with Si:Al ratio, correlating with increasing hydrophobicity (Fig. 8) which thus emerge as the most important factors controlling catalytic activity. Product selectivity to the acetic acid ester was $>99 \%$ for methanol, $n$-butanol and $p$-cresol; however, significant side products were observed for benzyl and anisyl alcohols. For benzyl alcohol, dibenzyl ether (the product of benzyl alcohol etherification) and an alkylation product formed, whereas anisyl alcohol only yielded the ester and ether: anisyl alcohol was more susceptible to etherification than benzyl alcohol. Figure S9 shows that the Si:Al ratio had little impact on the ester selectivity in acetic acid esterification with benzyl or anisyl alcohols. HFAU30 was subsequently evaluated for acetic acid esterification with methanol and benzyl alcohol to assess the impact of mesoporosity on mass transport. This revealed that a $30-50 \%$ increase in TOF for both alcohols as a result of increased acid site accessibility (and hydrophobicity).

The effect of acid:alcohol ratio on activity was also investigated, with reaction profiles shown in Fig. S10. Figure 9 reveals that increasing this ratio from $1: 5 \rightarrow 5: 1$ progressively

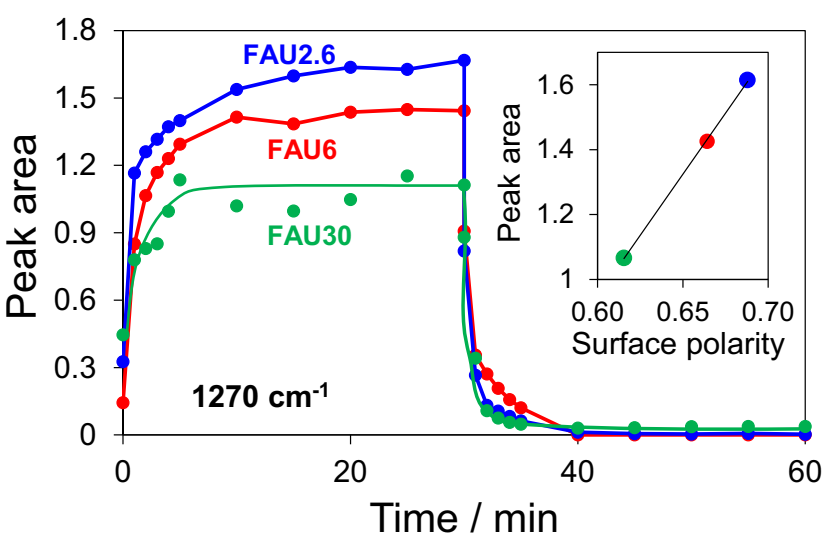

Fig. 5 Adsorption/desorption isotherms of acetic acid over FAU zeolites with different $\mathrm{Si}$ Al ratios. After $30 \mathrm{~min}$, the flow was changed from $0.1 \mathrm{M}$ acetic acid in methanol to pure methanol. (Inset) Area under peak $1270 \mathrm{~cm}^{-1}\left(\gamma_{\mathrm{C}-\mathrm{O}}\right)$ at saturation as a function of surface polarity

increased TOFs, consistent with a Langmuir-Hinshelwood bimolecular surface reaction, wherein strongly bound alcohol inhibits esterification [59].

The recyclability of FAU30 and HFAU30 was explored in acetic acid esterification with methanol in presence of toluene without any regeneration between the runs. No loss in catalytic activity was observed after three consecutive runs, indicating excellent recyclability of these catalysts under these reaction conditions.

The performance of FAU zeolites towards esterification pretreatment of a real bio-oil obtained by thermal pyrolysis of oak woodchips was subsequently explored in pressure flasks using excess methanol at $100{ }^{\circ} \mathrm{C}$. Figure 10 shows the resulting carboxylic acid conversions determined by titration. Acid conversion increased with Si:Al ratio and upon the introduction of hierarchical porosity, mirroring the observations from acetic acid esterification with model alcohols, albeit with lower conversions than observed for the simulated bio-oil, likely as a result of the water content of the pyrolysis oil (which may reversibly poison the acid sites) or presence of bulky organic components (e.g. oligomers/polymers) which may induce pore blockage [60].

In accordance with the results obtained for acetic acid esterification, HFAU30 was the most active catalyst for bio-oil esterification, and the esterified product from this catalyst was therefore analysed by GCxGC-ToFMS to identify products.
Table 2 Surface energy (SE) and polarity of FAU zeolites as a function of Si:Al ratio

\begin{tabular}{|c|c|c|c|c|c|}
\hline Catalyst & $\begin{array}{l}\text { Polar SE }\left(\gamma_{\mathrm{s}}^{\mathrm{p}}\right) / \\
\mathrm{mJ} \mathrm{m}^{-2}\end{array}$ & $\begin{array}{l}\text { Dispersive SE } \\
\left(\gamma_{\mathrm{s}}^{\mathrm{d}}\right) / \mathrm{mJ} \mathrm{m}^{-2}\end{array}$ & $\begin{array}{l}\text { Total SE }\left(\gamma_{\mathrm{s}}^{\mathrm{t}}\right) / \\
\mathrm{mJ} \mathrm{m}^{-2}\end{array}$ & $\begin{array}{l}\text { Surface } \\
\text { polarity }^{\mathrm{a}}\left(\gamma_{\mathrm{p}}\right)\end{array}$ & $\begin{array}{l}-\Delta \mathrm{G}_{\mathrm{ads}}{ }_{\mathrm{kJ}}^{\mathrm{SP}} \mathrm{MeOH} \\
\mathrm{kJol}\end{array}$ \\
\hline FAU2.6 & 193.8 & 87.9 & 281.7 & 0.69 & 18.7 \\
\hline FAU6 & 89.2 & 45.1 & 134.3 & 0.66 & 12.5 \\
\hline FAU30 & 118.5 & 74.0 & 192.5 & 0.62 & 12.2 \\
\hline HFAU30 & 68.0 & 74.4 & 142.4 & 0.48 & 10.6 \\
\hline
\end{tabular}

${ }^{\text {a }}$ Surface polarity $=$ polar SE/total SE 
Fig. 6 Bio-oil upgrading via esterification of acetic acid with various alcohols

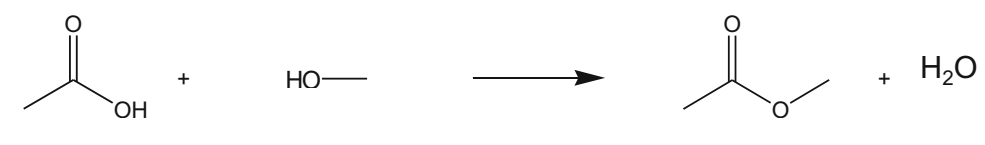

Acetic acid Methanol Methyl acetate

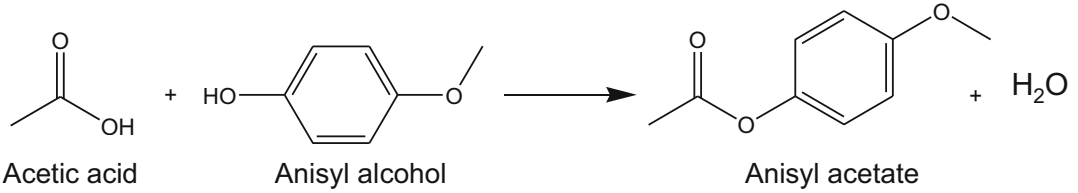<smiles>CC(=O)OC(=O)OCc1ccccc1</smiles>

Acetic acid

Benzyl alcohol

Benzyl acetate

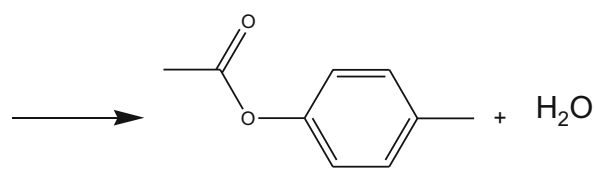

Acetic acid

p-cresol

p-cresyl acetate<smiles>CC(=O)O</smiles><smiles>CCCCO</smiles><smiles>CCCCOC(C)=O</smiles>

Acetic acid

$n$-butanol $n$-butyl acetate
Figures 11 and 12 show chromatograms of the initial and esterified bio-oils, respectively. In both cases, the chromatographic space is divided into six discreet areas: acids and esters, aldehydes and ketones (including furanoics and cyclic carbonyls), hydrocarbons (saturated and unsaturated nonaromatic), aromatic hydrocarbons, phenolic compounds, and sugars. Compounds that were not identified by the library and/or did not meet the required identification criteria were

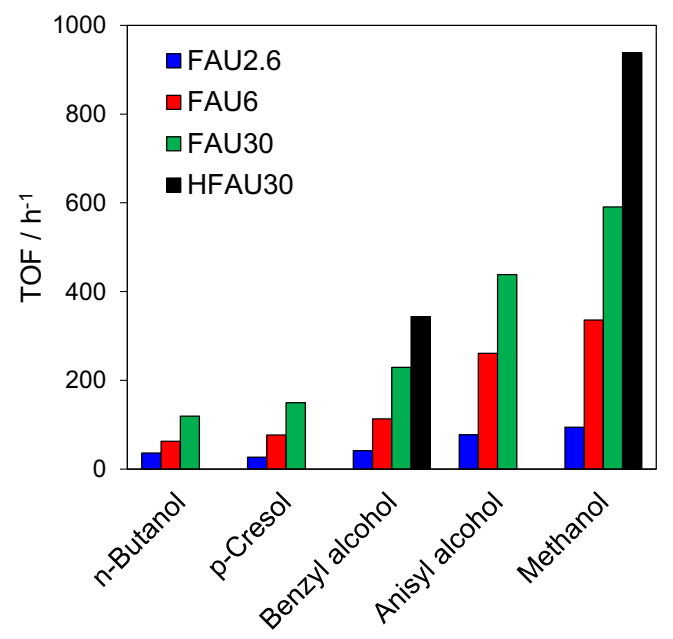

Fig. 7 TOFs for esterification of acetic acid with different alcohols over FAU zeolites with different Si:Al. (Reaction conditions: $5 \mathrm{mmol}$ acetic acid, acid:alcohol $=1: 5 \mathrm{~mol}: \mathrm{mol}, 10 \mathrm{ml}$ toluene, $100 \mathrm{mg}$ catalyst, $100{ }^{\circ} \mathrm{C}$ ) classified as 'unidentified'. Based on these criteria, a more detailed group classification of the compounds along with their relative chromatographic area is presented in Table 3.

Comparing the chromatograms of the initial (Fig. 11) and esterified bio-oil (Fig. 12), it is obvious that catalytic pretreatment altered the peak distribution in different

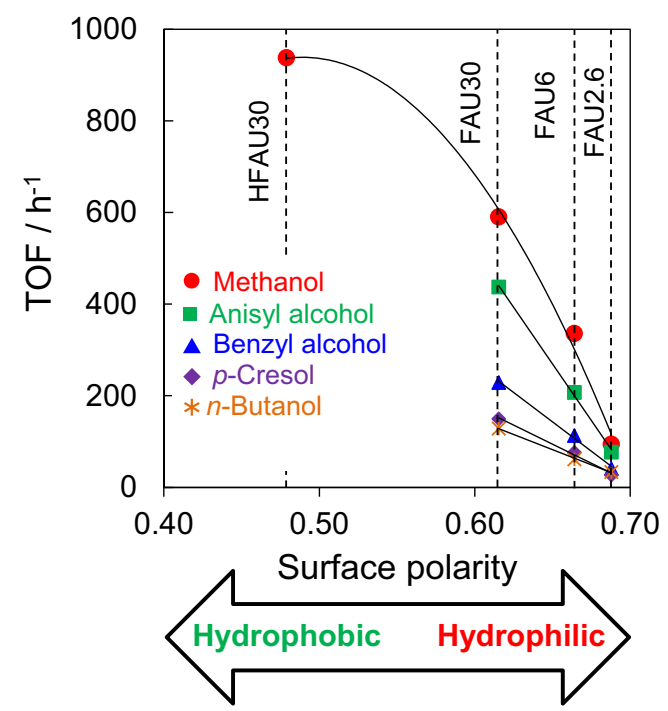

Fig. 8 TOFs as a function of FAU zeolites surface polarity. (Reaction conditions: $5 \mathrm{mmol}$ acetic acid, acid:alcohol $=1: 5 \mathrm{~mol}: \mathrm{mol}, 10 \mathrm{ml}$ toluene, $100 \mathrm{mg}$ catalyst, $100^{\circ} \mathrm{C}$ ) 


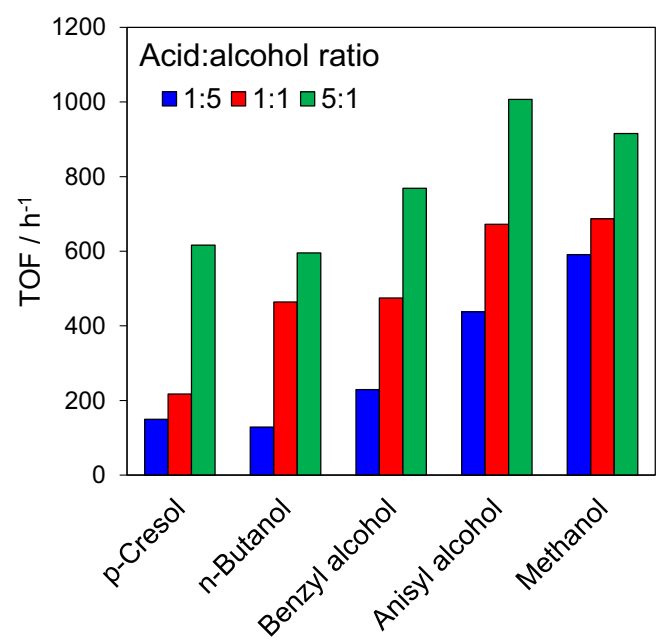

Fig. 9 TOFs for esterification of acetic acid with different alcohols over FAU30 at different acid:alcohol ratios. (Reaction conditions: $5 \mathrm{mmol}$ acid/alcohol, $10 \mathrm{ml}$ toluene, $100 \mathrm{mg}$ catalyst, $100{ }^{\circ} \mathrm{C}$ )

chromatographic areas. In particular, there is a significant reduction in the number of phenolic, aldehyde and ketone species [61], as quantified in Table 3. A few aromatic hydrocarbons detected in the initial bio-oil were also absent from the esterified one. A pronounced decrease in acetic acid (in the acids area) and levoglucosan (in the sugars area) was apparent from the esterified bio-oil chromatogram. The main peak in Figure 12 is attributed to methyl acetate (representing 34.3\% of the chromatographic area), verifying successful esterification of the principal acid present in the bio-oil. Smaller peaks corresponding to methyl propanoate and hexanoate were also detected. A peak attributed to glycolaldehyde dimenthyl acetal corresponds to the second highest peak area of the esterified bio-oil chromatogram. Previous studies have demonstrated that in alcohol media, levoglucosan can be transformed by

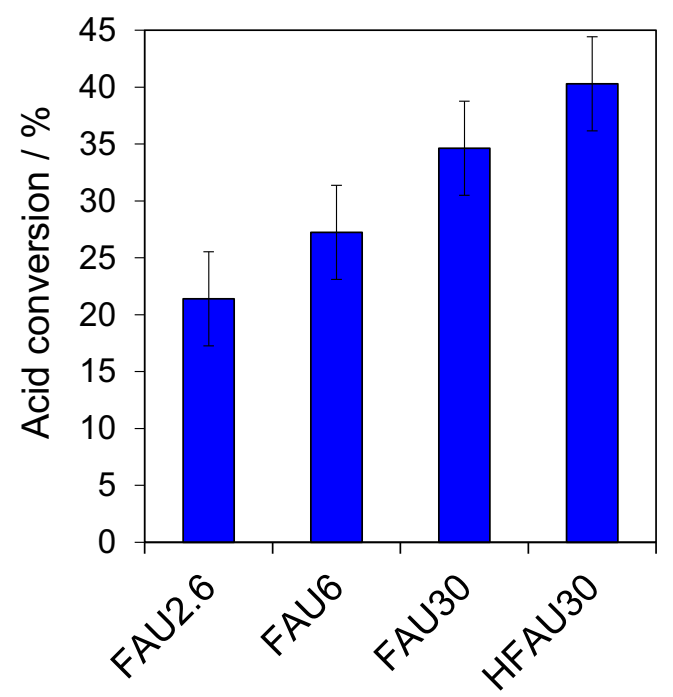

Fig. 10 Bio-oil acid conversion over FAU zeolites. (Reaction conditions: $4.5 \mathrm{~g}$ bio-oil (equivalent of $5 \mathrm{mmol}$ acid), $150 \mathrm{mmol}$ methanol, $100 \mathrm{mg}$ catalyst, $100{ }^{\circ} \mathrm{C}, 3 \mathrm{~h}$ )

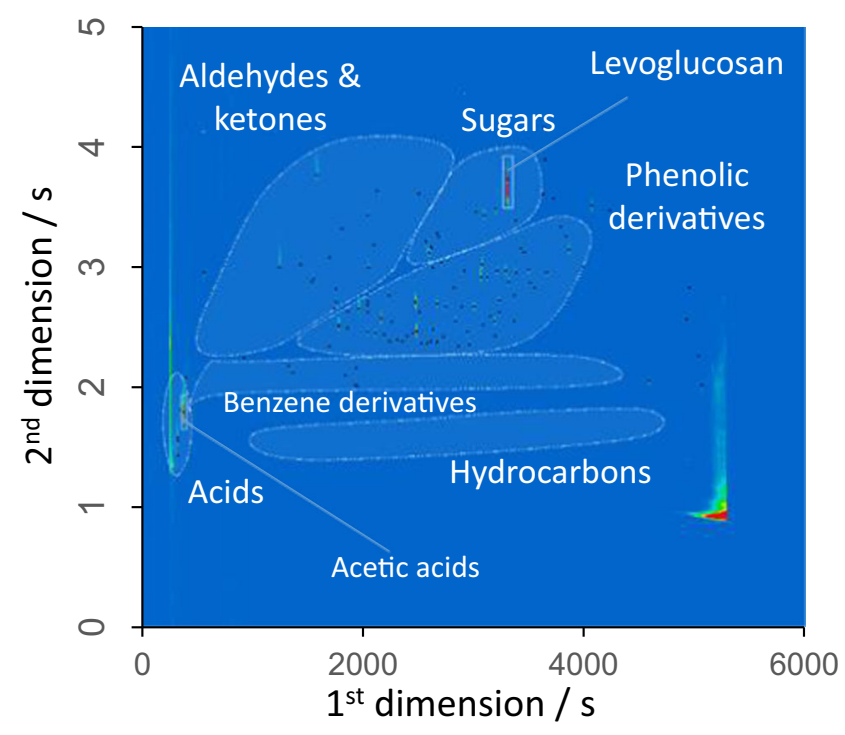

Fig. 11 GCxGC-ToFMS chromatogram of thermal pyrolysis bio-oil

acid catalysts to methyl levulinate with intermediate glycolaldehyde (GA) formation [62, 63]. However, under such conditions, GA may be partly deactivated via glycolaldehyde dimethyl acetal (GDA) formation. We propose that levoglucosan in the initial bio-oil was converted to GA (minor peak representing $0.2 \%$ of the chromatographic area, Fig. 12), which in turn formed GDA (major peak representing $32.2 \%$ of the chromatographic area, Fig. 12); methyl levulinate was not detected in the esterified bio-oil.

Deactivation of HFAU30 following esterification of thermal pyrolysis bio-oil was subsequently explored. Spent catalyst was divided into two portions: one washed with methanol and the other recalcined after a methanol wash with the goal of completely removing any carbon deposits. Temperatureprogrammed oxidation of an untreated spent catalyst revealed

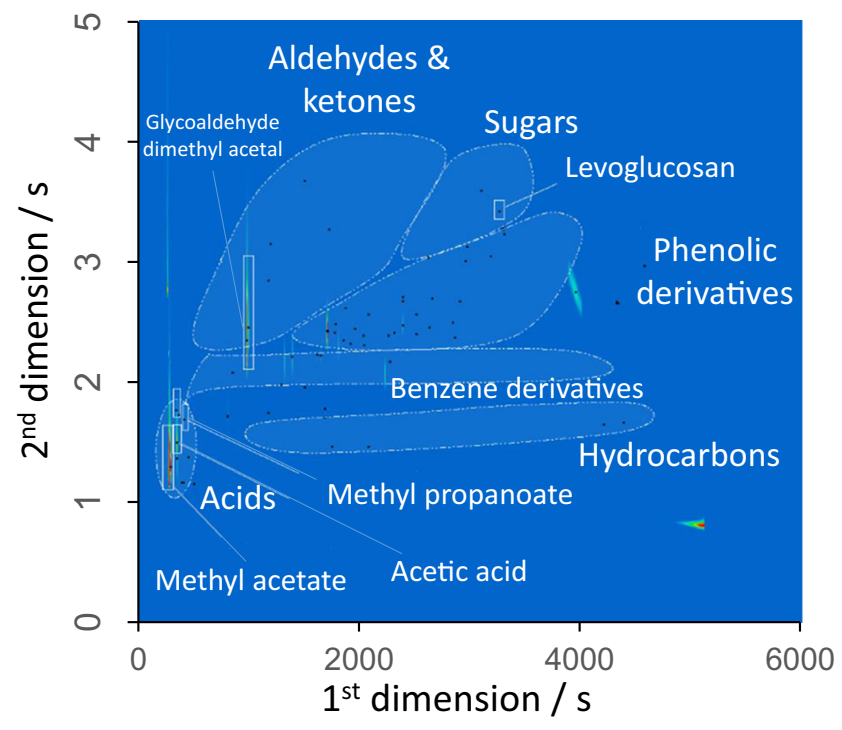

Fig. 12 GCxGC-ToFMS chromatogram of bio-oil after esterification over HFAU30 
Table 3 Peak distribution based on their relative chromatographic area $(\%)$

\begin{tabular}{lcl}
\hline Group & Bio-oil/area $\%$ & Esterified bio-oil/area \% \\
\hline Aromatic hydrocarbons & 1.76 & 0.08 \\
Aliphatic hydrocarbons & 0.37 & 0.58 \\
Phenolic compounds & 25.80 & 3.90 \\
Furanic compounds & 0.59 & 0.04 \\
Organic acids & 19.70 & 4.69 \\
Esters & 1.90 & 36.14 \\
Alcohols & 1.05 & 32.17 \\
Ethers & 1.01 & 4.81 \\
Aldehydes & 5.15 & 1.37 \\
Ketones & 10.81 & 3.15 \\
Sugars and anhydrosugars & 26.56 & 3.41 \\
N-compounds & 2.54 & 7.77 \\
Unidentified & 2.77 & 1.84 \\
\hline
\end{tabular}

the presence of $11 \mathrm{wt} \%$ carbonaceous residues post-reaction. Reuse of the methanol-washed catalyst revealed around $65 \%$ of its initial activity was lost. In contrast, recalcination fully regenerated the activity of the fresh HFAU30 catalyst, evidencing site blocking by strongly adsorbed carbonaceous species as the principle deactivation pathway.

\section{Conclusions}

A series of commercial FAU zeolites with different Si:Al ratios $(2.6 \rightarrow 30)$, and a hierarchically porous analogue of FAU30, were characterised by a range of bulk and surface sensitive analyses. IGC demonstrated that the hydrophobicity of FAU zeolites increases with Si:Al ratio, accompanied by a decrease in acid site loading, with minimal change in either acid strength or Lewis: Brønsted character. The introduction of pore hierarchy into the FAU30 structure further improved its physicochemical properties by enhancing hydrophobicity and acid site accessibility. Turnover frequencies for acetic acid esterification were proportional to the Si:Al ratio, suggesting that surface hydrophobicity plays an important role in displacing reactively formed water from surface acid sites; mesopores further promote esterification due to superior active site accessibility and surface hydrophobicity. Comparison of different aliphatic and aromatic alcohols revealed methanol as the most reactive, likely due to a combination of electronic and steric effects and superior in-pore diffusion to active sites. The hierarchical FAU30 catalyst proved efficient for the upgrading of bio-oil obtained from thermal pyrolysis of oak woodchips via esterification with methanol under mild conditions.
Acknowledgements We thank the EPSRC for financial support (EP/ $\mathrm{K} 000616 / 2, \mathrm{EP} / \mathrm{G} 007594 / 4, \mathrm{EP} / \mathrm{K} 036548 / 2$ and EP/N009924/1) and the award of a Leadership Fellowship to AFL. KW thanks the Royal Society for an Industry Fellowship. Support from the European Union Seventh Framework Programme (FP7/2007-2013) under grant agreement no. 604307 is also greatly acknowledged. Underpinning data can be found at 10.17036/researchdata.aston.ac.uk.00000216.

Open Access This article is distributed under the terms of the Creative Commons Attribution 4.0 International License (http:// creativecommons.org/licenses/by/4.0/), which permits unrestricted use, distribution, and reproduction in any medium, provided you give appropriate credit to the original author(s) and the source, provide a link to the Creative Commons license, and indicate if changes were made.

\section{References}

1. Armaroli N, Balzani V (2007) The future of energy supply: Challenges and opportunities. Angew Chem-Int Edit 46:52-66

2. Asefa T, MacLachlan MJ, Coombs N, Ozin GA (1999) Periodic mesoporous organosilicas with organic groups inside the channel walls. Nature 402:867-871

3. Lee AF, Bennett JA, Manayil JC, Wilson K (2014) Heterogeneous catalysis for sustainable biodiesel production via esterification and transesterification. Chem Soc Rev 43:7887-7916

4. Xiu S, Shahbazi A (2012) Bio-oil production and upgrading research: A review. Renew Sust Energ Rev 16:4406-4414

5. Wilson K, Lee AF (2012) Rational design of heterogeneous catalysts for biodiesel synthesis. Catalysis Science \& Technology 2: 884-897

6. Ciddor L, Bennett JA, Hunns JA, Wilson K, Lee AF (2015) Catalytic upgrading of bio-oils by esterification. J Chem Technol Biotechnol 90:780-795

7. Dhainaut J, Dacquin J-P, Lee AF, Wilson K (2010) Hierarchical macroporous-mesoporous SBA-15 sulfonic acid catalysts for biodiesel synthesis. Green Chem 12:296-303

8. Ni J, Meunier FC (2007) Esterification of free fatty acids in sunflower oil over solid acid catalysts using batch and fixed bed-reactors. Appl Catal A Gen 333:122-130

9. López DE, Goodwin JG Jr, Bruce DA, Furuta S (2008) Esterification and transesterification using modified-zirconia catalysts. Appl Catal A Gen 339:76-83

10. Chen X-R, Ju Y-H, Mou C-Y (2007) Direct Synthesis of Mesoporous Sulfated Silica-Zirconia Catalysts with High Catalytic Activity for Biodiesel via Esterification. J Phys Chem C 111:18731-18737

11. Mbaraka IK, Radu DR, Lin VSY, Shanks BH (2003) Organosulfonic acid-functionalized mesoporous silicas for the esterification of fatty acid. J Catal 219:329-336

12. Melero JA, Bautista LF, Morales G, Iglesias J, Briones D (2008) Biodiesel Production with Heterogeneous Sulfonic AcidFunctionalized Mesostructured Catalysts. Energy Fuel 23:539-547

13. Garg S, Soni K, Kumaran GM, Bal R, Gora-Marek K, Gupta JK, Sharma LD, Dhar GM (2009) Acidity and catalytic activities of sulfated zirconia inside SBA-15. Catal Today 141:125-129

14. Dacquin JP, Lee AF, Pirez C, Wilson K (2012) Pore-expanded SBA-15 sulfonic acid silicas for biodiesel synthesis. Chem Commun 48:212-214

15. Pirez C, Lee AF, Manayil JC, Parlett CMA, Wilson K (2014) Hydrothermal saline promoted grafting: a route to sulfonic acid SBA-15 silica with ultra-high acid site loading for biodiesel synthesis. Green Chem 16:4506-4509 
16. Pirez C, Caderon J-M, Dacquin J-P, Lee AF, Wilson K (2012) Tunable KIT-6 Mesoporous Sulfonic Acid Catalysts for Fatty Acid Esterification. ACS Catal 2:1607-1614

17. Pirez C, Reche MT, Lee AF, Manayil JC, dos-Santos VC, Wilson K (2015) Hydrothermal Saline Promoted Grafting of Periodic Mesoporous Organic Sulfonic Acid Silicas for Sustainable FAME Production. Catal Lett 145:1483-1490

18. Alsalme A, Kozhevnikova EF, Kozhevnikov IV (2008) Heteropoly acids as catalysts for liquid-phase esterification and transesterification. Appl Catal A Gen 349:170-176

19. Leng Y, Wang J, Zhu D, Wu Y, Zhao P (2009) Sulfonated organic heteropolyacid salts: Recyclable green solid catalysts for esterifications. J Mol Catal A Chem 313:1-6

20. Dufaud V, Lefebvre F, Niccolai GP, Aouine M (2009) New insights into the encapsulation and stabilization of heteropolyacids inside the pore walls of mesostructured silica materials. J Mater Chem 19:1142-1150

21. Narasimharao K, Brown DR, Lee AF, Newman AD, Siril PF, Tavener SJ, Wilson K (2007) Structure-activity relations in Csdoped heteropolyacid catalysts for biodiesel production. J Catal 248:226-234

22. Pesaresi L, Brown DR, Lee AF, Montero JM, Williams H, Wilson K (2009) Cs-doped H4SiW12O40 catalysts for biodiesel applications. Appl Catal A Gen 360:50-58

23. López DE, Suwannakarn K, Bruce DA, Goodwin JG Jr (2007) Esterification and transesterification on tungstated zirconia: Effect of calcination temperature. J Catal 247:43-50

24. Ngaosuwan K, Mo X, Goodwin JG Jr, Praserthdam P (2010) Effect of solvent on hydrolysis and transesterification reactions on tungstated zirconia. Appl Catal A Gen 380:81-86

25. Ngaosuwan K, Mo X, Goodwin JG, Praserthdam P (2010) Reaction Kinetics and Mechanisms for Hydrolysis and Transesterification of Triglycerides on Tungstated Zirconia. Top Catal 53:783-794

26. Rao KN, Sridhar A, Lee AF, Tavener SJ, Young NA, Wilson K (2006) Zirconium phosphate supported tungsten oxide solid acid catalysts for the esterification of palmitic acid. Green Chem 8:790 797

27. Melero JA, Iglesias J, Morales G (2009) Heterogeneous acid catalysts for biodiesel production: current status and future challenges. Green Chem 11:1285-1308

28. Corma A, Garcia H, Iborra S, Primo J (1989) Modified faujasite zeolites as catalysts in organic reactions: Esterification of carboxylic acids in the presence of HY zeolites. J Catal 120:78-87

29. Kirumakki SR, Nagaraju N, Narayanan S (2004) A comparative esterification of benzyl alcohol with acetic acid over zeolites $H \beta$, HY and HZSM5. Appl Catal A Gen 273:1-9

30. Ferreira P, Fonseca IM, Ramos AM, Vital J, Castanheiro JE (2009) Esterification of glycerol with acetic acid over dodecamolybdophosphoric acid encaged in USY zeolite. Catal Commun 10:481-484

31. Kubička D, Kubičková I, Čejka J (2013) Application of Molecular Sieves in Transformations of Biomass and Biomass-Derived Feedstocks. Catal Rev 55:1-78

32. Pu X, Liu N-w, Shi L (2015) Acid properties and catalysis of USY zeolite with different extra-framework aluminum concentration. Microporous Mesoporous Mater 201:17-23

33. Yan Z, Ma D, Zhuang J, Liu X, Liu X, Han X, Bao X, Chang F, Xu L, Liu Z (2003) On the acid-dealumination of USY zeolite: a solid state NMR investigation. J Mol Catal A Chem 194:153-167

34. Verboekend D, Perez-Ramirez J (2011) Design of hierarchical zeolite catalysts by desilication. Catalysis Science \& Technology 1: 879-890

35. Milina M, Mitchell S, Michels N-L, Kenvin J, Pérez-Ramírez J (2013) Interdependence between porosity, acidity, and catalytic performance in hierarchical ZSM-5 zeolites prepared by post-synthetic modification. J Catal 308:398-407
36. Cho HJ, Dornath P, Fan W (2014) Synthesis of Hierarchical SnMFI as Lewis Acid Catalysts for Isomerization of Cellulosic Sugars. ACS Catal 4:2029-2037

37. Huang S, Liu X, Yu L, Miao S, Liu Z, Zhang S, Xie S, Xu L (2014) Preparation of hierarchical mordenite zeolites by sequential steaming-acid leaching-alkaline treatment. Microporous Mesoporous Mater 191:18-26

38. Serrano DP, Sanz R, Pizarro P, Moreno I, Shami S (2014) Narrowing the mesopore size distribution in hierarchical TS-1 zeolite by surfactant-assisted reorganization. Microporous Mesoporous Mater 189:71-82

39. Jiang J, Yu J, Corma A (2010) Extra-Large-Pore Zeolites: Bridging the Gap between Micro and Mesoporous Structures. Angew Chem Int Ed 49:3120-3145

40. Perez-Ramirez J, Christensen $\mathrm{CH}$, Egeblad $\mathrm{K}$, Christensen $\mathrm{CH}$, Groen JC (2008) Hierarchical zeolites: enhanced utilisation of microporous crystals in catalysis by advances in materials design. Chem Soc Rev 37:2530-2542

41. Čimek A, Subotić B, Šmit I, Tonejc A, Aiello R, Crea F, Nastro A (1997) Dissolution of high-silica zeolites in alkaline solutions II. Dissolution of 'activated' silicalite-1 and ZSM-5 with different aluminum content. Microporous Materials 8:159-169

42. Mitchell S, Pinar AB, Kenvin J, Crivelli P, Kärger J, Pérez-Ramírez J (2015) Structural analysis of hierarchically organized zeolites. Nat Commun 6:8633

43. Opanasenko MV, Roth WJ, Cejka J (2016) Two-dimensional zeolites in catalysis: current status and perspectives. Catalysis Science \& Technology 6:2467-2484

44. Milina M, Mitchell S, Pérez-Ramírez J (2014) Prospectives for biooil upgrading via esterification over zeolite catalysts. Catal Today 235:176-183

45. Gutierrez MC, Rubio J, Rubio F, Oteo JL (1999) Inverse gas chromatography: a new approach to the estimation of specific interactions. J Chromatogr A 845:53-66

46. Newell HE, Buckton G, Butler DA, Thielmann F, Williams DR The Use of Inverse Phase Gas Chromatography to Measure the Surface Energy of Crystalline, Amorphous, and Recently Milled Lactose. Pharm Res, 18:662-666

47. Kim JS, Friend RH, Cacialli F (1999) Surface energy and polarity of treated indium-tin-oxide anodes for polymer light-emitting diodes studied by contact-angle measurements. J Appl Phys 86: 2774-2778

48. Roby SH, Dutta M, Zhu Y, Pathiparampil A (2015) Development of an Acid Titration for Fast Pyrolysis Oil. Energy Fuel 29:858-862

49. Michailof C, Sfetsas T, Stefanidis S, Kalogiannis K, Theodoridis G, Lappas A (2014) Quantitative and qualitative analysis of hemicellulose, cellulose and lignin bio-oils by comprehensive two-dimensional gas chromatography with time-of-flight mass spectrometry. J Chromatogr A 1369:147-160

50. Verboekend D, Vilé G, Pérez-Ramírez J (2012) Hierarchical Y and USY Zeolites Designed by Post-Synthetic Strategies. Adv Funct Mater 22:916-928

51. Keller TC, Arras J, Wershofen S, Pérez-Ramírez J (2015) Design of Hierarchical Zeolite Catalysts for the Manufacture of Polyurethane Intermediates. ACS Catal 5:734-743

52. Parlett CMA, Durndell LJ, Machado A, Cibin G, Bruce DW, Hondow NS, Wilson K, Lee AF (2014) Alumina-grafted SBA-15 as a high performance support for Pd-catalysed cinnamyl alcohol selective oxidation. Catal Today 229:46-55

53. Silaghi M-C, Chizallet C, Raybaud P (2014) Challenges on molecular aspects of dealumination and desilication of zeolites. Microporous Mesoporous Mater 191:82-96

54. Das SC, Larson I, Morton DAV, Stewart PJ (2011) Determination of the Polar and Total Surface Energy Distributions of Particulates by Inverse Gas Chromatography. Langmuir 27:521-523 
55. Peters TA, Benes NE, Holmen A, Keurentjes JTF (2006) Comparison of commercial solid acid catalysts for the esterification of acetic acid with butanol. Appl Catal A Gen 297:182-188

56. Chen NY (1976) Hydrophobic properties of zeolites. J Phys Chem 80:60-64

57. Klein S, Maier WF (1996) Microporous Mixed Oxides - Catalysts with Tunable Surface Polarity. Angew Chem Int Ed Engl 35:2230 2233

58. Kukulska-Zając E, Góra-Marek K, Datka J (2006) IR and TPD studies of the reaction of acetic acid in zeolites NaHY. Microporous Mesoporous Mater 96:216-221

59. Osatiashtiani A, Durndell LJ, Manayil JC, Lee AF, Wilson K (2016) Influence of alkyl chain length on sulfated zirconia catalysed batch and continuous esterification of carboxylic acids by light alcohols. Green Chem 18:5529-5535
60. Hu X, Wang Y, Mourant D, Gunawan R, Lievens C, Chaiwat W, Gholizadeh M, Wu L, Li X, Li C-Z (2013) Polymerization on heating up of bio-oil: A model compound study. AICHE J 59: 888-900

61. Hilten R, Weber J, Kastner JR (2016) Continuous Upgrading of Fast Pyrolysis Oil by Simultaneous Esterification and Hydrogenation. Energy Fuel 30:8357-8368

62. Holm MS, Pagan-Torres YJ, Saravanamurugan S, Riisager A, Dumesic JA, Taarning E (2012) Sn-Beta catalysed conversion of hemicellulosic sugars. Green Chem 14:702-706

63. $\mathrm{Hu} \mathrm{X}, \mathrm{Wu} \mathrm{L}$, Wang Y, Mourant D, Lievens C, Gunawan R, Li C-Z (2012) Mediating acid-catalyzed conversion of levoglucosan into platform chemicals with various solvents. Green Chem 14:30873098 